\title{
Aristóteles y Spinoza: algunas consideraciones ontológicas
}

\section{Eduardo González Murillo}

Licenciado en Docencia con Énfasis en Filosofía por la Universidad Estatal a Distancia (UNED) y bachiller en Enseñanza de la Filosofía por la Universidad de Costa Rica. Tutor de la Cátedra de Filosofía en la Escuela de Ciencias Sociales y Humanidades de la UNED. Dirección electrónica: almatica@yahoo.com

Recibido: 24 de Enero 2013 • Aceptado: 12 de Abril 2013

\section{RESUMEN}

En este artículo se exponen las tesis ontológicas de Aristóteles y Spinoza; se analizan las convergencias y divergencias de sus tesis. Luego, se comparan los aspectos relacionados con el ser y la sustancia, según ambos autores; también, se establecen las semejanzas y diferencias entre los conceptos de ser, sustancia, modo y accidente. Por último, se relaciona la aplicación spinoziana de los conceptos de causa eficiente y causa final con los de Aristóteles.

Palabras clave: Metafísica, ontología, Aristóteles, Spinoza.

\section{ABSTRACT}

Aristotle and Spinoza: Some Ontological Considerations. Through this article, it is exposed the ontological thesis of Aristotle and Spinoza. It is analyzed the convergences and divergences of their thesis. After, according to both authors the aspects related to the being and substance are compared. Also, there is established the similarities and the differences among the concepts of being, substance, mode, and accident. Finally, it is related the Spinoza's application to the concepts of efficient cause and final cause with Aristotle's.

Key words: Metaphysics, ontology, Aristotle, Spinoza.

\section{La filosofía de Spinoza: consideraciones liminares}

Spinoza es un continuador de la filosofía de Descartes: también acepta y propone una metafísica de la substancia; sin embargo, Spinoza se distancia cuando se opone al dualismo y parte, precisamente, de la negación del principio de la distinción entre el cuerpo y la mente.

La filosofía de Spinoza tiene una concepción fundamentalmente teológica y ética, pero parte de una metafísica que sería una filosofía de identidad, i.e., el monismo o el panteísmo consumado; scil, la identificación de Dios (única substancia) con el mundo; propiamente, cuando se dice que la mente humana es parte del entendimiento infinito de Dios, que de Él se sigue necesariamente todo, que el alma particular se identifica con el todo, etc. En términos generales, alude al inmanentismo de índole panteísta (según lo expuesto en su obra magna Ética demostrada según el orden geométrico).

La filosofía spinoziana posee una proclividad práctica, ya que quiere llegar a una solución al problema moral del hombre a través de una convicción racional, de llegar a la beatitud y, es así, como culmina su metafísica: en la conclusión ética del amor Dei intellectualis (amor intelectual 
de Dios); así tendríamos, como nos muestra Dujovne (1943), que serían dos corrientes: “[...] una metafísica que parte de Dios, y otra moral, que lleva a Dios" (p. 41).

Dios es la substancia, la esencia de las cosas y una de las maneras de manifestarse es por medio del alma. Ya sabemos que el alma humana es parte de Dios (c.f. Corolario de la Proposición XI, $2^{\mathrm{a}}$ Parte, Ética). Tendríamos, así, grados de ostentación divina puesto que Dios no se manifiesta con igual intensidad en todos los hombres; más bien, en cuanto mejor obremos, más intensamente está Dios en nosotros (deriva ética).

Por eso, la base en la cual se fundamenta el monismo spinoziano se hace patente en la primera parte de la Ética demostrada según el orden geométrico. Veamos algunas de las proposiciones que demuestran lo anterior: Primeramente, se hace alusión a que "[...] en el orden natural no pueden darse dos o más substancias de la misma naturaleza, o sea, con el mismo atributo" (Spinoza, 2004: 49).

Se deduce de lo anterior que, si hubiese más de dos substancias, deberían distinguirse; ya sea por la diversidad de atributos, o por la diversidad de las afecciones (cf. proposición IV). Ahora bien, si se distinguieran por la diversidad de los atributos se daría una substancia del mismo atributo, $\mathrm{y}$, si fuera por la diversidad de afecciones, sería imposible, puesto que la substancia es anterior a sus afecciones (cf. Proposición I). Además de lo anterior, se dice que una substancia no puede ser producida por otra; o sea, dos substancias que posean el mismo atributo y que tengan algo en común entre sí; de ser así, una no puede ser causa de la otra (cf. Demostración de la Proposición VI) además, si se produjera por otra cosa, el conocimiento de esta sustancia dependería del conocimiento de su causa; esto fundamentado en el Axioma IV y de la Definición III.

Para Spinoza Dios es único y la pluralidad de entes finitos es el infinito conjunto de las modificaciones de la substancia; existe por sí (causa sui), existe necesariamente, consta de infinitos atributos de los cuales expresan una esencia eterna e infinita; es indivisible, es res cogitans y res extensa (en términos cartesianos), es causa eficiente y causa esencial. Se identifica con la única substancia; por lo tanto, sus atributos son los atributos infinitos de Dios.

Dios es naturaleza y, según lo propuesto y explicado por Spinoza, se puede entender en dos sentidos. Veámoslo de la siguiente manera. Spinoza propone en el escolio de la Proposición XXIX:

Escolio: Antes de seguir adelante, quiero explicar aquí -o más bien advertir- qué debe entenderse por naturaleza naturante y qué por naturaleza naturada. Pues, por lo que antecede, estimo que ya consta, a saber, que por naturaleza naturalizante debemos entender aquello que es en sí y se concibe por sí, o sea, aquellos atributos de la substancia que expresan una esencia eterna e infinita, esto es (por el Corolario 1 de la Proposición 14 y el Corolario 2 de la Proposición 17), Dios, en cuanto se lo considera como una causa libre. Por $\mathrm{Na}$ turaleza naturalizada, en cambio, entiendo todo aquello que se sigue de la necesidad de la naturaleza de Dios, o sea, de la de cada uno de los atributos de Dios; esto es, todos los modos de los atributos de Dios, en cuanto se los considera como cosas que son en Dios y que sin Dios no pueden ni ser, ni concebirse (Spinoza, 2004: 83).

Ahora bien, de Dios se sigue todas las cosas:

- "Todo lo que es, es en Dios; y nada puede ser ni concebirse sin Dios." (Proposición $X V$, Ibíd.).

- "Corolario I: De aquí se sigue: $1^{\circ}$ que Dios es causa eficiente de todas las cosas que pueden caer bajo un entendimiento infinito."

- "Corolario II: Se sigue: $2^{\circ}$ que Dios es causa por sí, pero no por accidente."

- "Corolario III: Se sigue: $3^{\circ}$ que Dios es absolutamente causa primera." (Corolarios de la Proposición XVI, Ibíd.).

- "Dios no es sólo causa eficiente de la existencia de las cosas, sino también de su esencia." (Proposición $X X V$, Ibíd.). 
Con lo anterior, y lo mencionado en el escolio de la proposición XXVIII, scil., que Dios es causa absolutamente próxima de las cosas producidas por Él inmediatamente. Se ve, pues, que Dios sería naturaleza en cuanto todas las cosas proceden de Él; o sea, que es el origen de todas las cosas y, en otro sentido en que las cosas emergen, que Dios no hace nada distinto de Él: hace las cosas con suma perfección y son consideradas en Dios, además, que sin Él no pueden existir. Esto es lo que Spinoza llama natura naturata.

Así Dios no existe fuera de la naturaleza, puesto que es ella misma; todas las cosas manifiestas del mundo son atributos de esta substancia: "Por atributo entiendo aquello que el entendimiento percibe de una substancia como constitutivo de la esencia de la misma" (Definición IV, $1^{a}$ Parte, Spinoza, 2004: 46).

Acá es donde se manifiesta el panteísmo spinoziano, sin embargo, sólo se conocen dos atributos de Dios: la res cogitans y la res exten$s a$. En consecuencia se da por sentado que Dios es naturaleza y esta es parte de Él; o sea, que nada puede existir fuera de este: todo se reduce naturalmente a Dios.

El monismo se acrecienta más cuando se destruye la dualidad de Dios y el mundo; se explica a través de que el alma humana es una parte del entendimiento infinito de Dios, y que cuando el alma humana percibe cualquier cosa, no es más que Dios que tiene la idea de estas cosas. (cf. Corolario de la Proposición 11, $2^{\text {a }}$ Parte de la Ética)

Dios obra por las solas leyes de la naturaleza sin ser obligado por nadie, de acá se infiere que de Dios se sigue una absoluta infinidad de cosas y esto Spinoza lo sustenta con la explicación de que Dios es causa eficiente y absolutamente primera (tesis monista).

\section{Ontología spinoziana y aristotélica: necesidad y contingencia}

El texto capital que trata explícitamente el ser es Pensamientos metafísicos (Cogitata metaphysica). A partir de este libro se hará el análisis y se remitirá a otras fuentes cuando sea necesario, puesto que Spinoza, en este tratado, deja de lado lo concerniente a la substancia, las causas y los modos.

Como cuestión liminar, Spinoza da una definición del ser: "Comencemos, pues, por el ser, por él entiendo todo aquello que, cuando se percibe clara y distintamente, comprobamos que existe necesariamente o que, al menos, puede existir" (Spinoza, 1988: 230). Hasta aquí tenemos una división del ser, a saber, en ser necesario y en ser contingente. En esta cita, Spinoza propone lo siguiente: si compruebo fuera de mi mente, o sea, en lo físico (lo tangible, lo sensible) que existe o que pudo no haber existido cualquier cosa, entonces, esa cosa es un ser. Algo más que aclara de modo simplificado: si compruebo que esa cosa es necesaria o contingente, entonces, es un ser. Más adelante Spinoza dice que la quimera, el ser ficticio (la cursiva es mía) y ente de razón, no son seres por definición (su definición) ya que la quimera por su propia naturaleza no puede existir (quimera acá significaría ficción, ilusión, etc. y su naturaleza sería meramente nominal); pasa lo mismo con el ser ficticio y el ente de razón que no es más que un modo de pensar. A partir de este último ente de razón, Spinoza esboza que es incorrecto dividir el ser en ente real y ente de razón puesto que sería como dividir el ser en ser y no-ser (Ibíd.: 232). De ser lo contrario, estaría negando el principio de no-contradicción, y es imposible ser y no ser a la vez. Además, esta división se nota incluso en Aristóteles: ser necesario per se y ser per accidens, que correspondería respectivamente al ente necesario y al ente contingente en Spinoza. Esto último se retomará en líneas posteriores.

Así, el ser real de Spinoza es causa sui, ya que su esencia implica la existencia (Ibíd.: 233), y con esto nos remitimos a la primera definición de la ética: "[...] por causa de sí entiendo aquello cuya esencia implica la existencia, o sea, aquello cuya naturaleza no puede concebirse sino como existente" (Spinoza, 2004: 45).

Ahora bien, de esto podemos decir que en el ser real la esencia envuelve la existencia; o sea, que la una es necesariamente consecuencia de la otra, además, que son necesariamente concomitantes. 
Podemos contrastar esto con Aristóteles. Primero veamos algo con respecto a la definición de "necesario", con el fin de aclarar ciertos asuntos para plantear las próximas líneas. Necesario es aquello sin lo cual, por ser concausa, no se puede vivir y, además, lo que no puede ser de otro modo que como es; estas son dos de las definiciones de necesario que son pertinentes al caso (Aristóteles, Metafísica V, V. 1015a). Con lo anterior, para Aristóteles el ser se dice, ya en sí mismo o en otro; y que "ser" y "es" significan que algo es verdadero (cf. Metafisica. V, VII). En Spinoza se puede ver que " $[\ldots]$ la idea verdadera es aquella que nos muestra la cosa tal como es" (Spinoza, 1988: 245), así habría una similitud con el concepto del Estagirita.

En Aristóteles hay un proyecto metafísico y se podría decir que científico también. Se trata de buscar los principios y las causas de las cosas que son (cf. op. cit. VI, I. 1025b); o sea, una ciencia del ser, una ciencia teorética. Existe el problema de aceptar si esta ciencia es posible. Ahora bien, para que esta sea posible, debe reducir los significados del ser a un único significado fundamental, puesto que el ser se dice de muchas maneras. Para ello, debe reconocer el principio de no-contradicción, con este principio se nota que el ser en Aristóteles es necesario, puesto que es imposible que el ser no sea. Además, se podría decir que ese ser, primeramente, significa el qué-es y algo determinado. Cosa que entrañaría una determinación del ser, puesto que: "[...] uno solo era, en efecto, su significado y este era la entidad de algo. Ahora bien, significar la entidad (de una cosa〉 es «significar> que el ser de tal cosa no es algo distinto" (Ibíd. IV, IV. 1007a, 25).

Existe, además, un ser necesario y Franz Brentano sintetiza parte de este tratado de la siguiente forma:

Existe un ser necesario por sí, infinitamente perfecto, primer fundamento de toda realidad, principio eficiente per se, no per accidens (o sea, causa eficiente puesto que en Aristóteles todas las causas son principios; sin embargo, decir que ese ser necesario es causa eficiente presenta alguna inconsistencia que tratará posteriormente que el autor citado no explica), y que en él se observe la ley de sinonimia, o sea, que la causa es sinónima de su efecto (Brentano, 1951: 81).

Ese ser necesario es el "primer motor" que se tratará en las líneas próximas.

Hasta aquí vemos algo comparable con Spinoza que es determinista. Esto se demuestra de la siguiente manera en los axiomas de la primera parte de la Ética demostrada según el orden geométrico:

- "III. Dada una determinada causa, de ella se sigue necesariamente un efecto y, al contrario, si no se da ninguna causa determinada, es imposible que siga un efecto".

- "IV. El conocimiento del efecto depende del conocimiento de la causa y lo implica".

- "V. Las cosas que no tienen nada de común una con otra, tampoco pueden entenderse una por otra; o sea, el concepto de una no implica el concepto de otra" (Spinoza, 2004: 48).

Pero lo citado se expondrá cuando se hable acerca de la causas. Por ahora, solo se trajo a colación para asentar el determinismo spinoziano.

En Aristóteles, ese ser necesario por sí, infinitamente perfecto, primer fundamento de toda realidad, principio eficiente per se, no per accidens; del que se habló anteriormente, sería la substancia única para Spinoza. Se nota una diferencia en cuanto a la aplicación del término de substancia. Para el Estagirita, la substancia (entidad, ousía) se dice de muchas maneras: como cuerpos simples; lo que es causa inmanente del ser de aquellas cosas que no se predican de un sujeto, las partes inmanentes de tales cosas y como esencia (cf. Metafísica V, VIII). En ese sentido, la substancia es la causa primera del ser propio de cada realidad determinada; en Spinoza, la substancia se identifica con Dios y es ciertamente causa primera; sin embargo; difieren. Esto se amplía a continuación:

Lo anterior se nota cuando Aristóteles insiste en que el ser, primeramente, significa el quées y algo determinado; o sea, la entidad (ousía) 
y esta remite al ser en sí mismo. Además, agrega Aristóteles, preguntar ¿qué es lo qué es?, es lo mismo que preguntar ¿qué es la entidad? Luego se entiende como categorías o accidentes: la cualidad, la cantidad o cualquier otra de las cosas que se predican de este modo. Estos últimos coincidirían con lo entes de razón expuestos por Spinoza, ya que los entes de los que habla Aristóteles no existen por sí.

Por otro lado, y como se dijo anteriormente, la substancia en Spinoza se identifica con Dios, existe necesariamente y de este se sigue que es causa primera y de todas las cosas, en este caso sería causa eficiente y causa esencial. Lo vemos cuando Spinoza se refiere a que "Dios no es solo causa eficiente de la existencia de las cosas, sino también de su esencia" (Spinoza, 2004: 79).

Dios, o sea, la substancia única; puesto que es ilimitada e infinita, tiene infinito número de atributos (atributo: aquello que el entendimiento percibe de la substancia en cuanto que constituye la esencia de la misma); de lo contrario, estaría limitada por algo y se estaría en una contradicción porque, para comprender el concepto de substancia, se estaría acudiendo al concepto de la cosa que la limita y que está fuera de ella. Esta substancia única es causa de todas las cosas, pero estas cosas no son substancias independientes (es la natura naturata), serían modos o estados de la substancia única. Acá vemos algo capital en esta comparación: en Aristóteles se hace patente una pluralidad de substancias, o sea, los seres existentes, cuerpos simples, etc., estos serían los modos de Spinoza y la substancia única de este último sería el primer motor de Aristóteles.

Hablemos de esa substancia inmóvil de Aristóteles. Se nota una especie de clasificación en cuanto a las substancias determinadas existentes en el mundo y de dónde provienen. Veámoslo de la siguiente manera: existe una substancia inmóvil y es eterna e inmaterial. Esta necesidad surge para explicar la continuidad y la eternidad del movimiento de los cielos. El primer cielo debe tener como causa un primer motor, el cual regula el movimiento (no solo existe este cielo, porque hay movimiento de las demás esferas celestes; además, Aristóteles admite otros en los cuales hay un primer motor). Este primer motor se identifica con Dios, y al igual que en Spinoza es en sí, se concibe por sí, es causa de sí y es causa primera. El sentido de primer motor no debe entenderse en sentido temporal (puesto que el movimiento es eterno), sería, más bien, un sentido de supremo. Este primer motor debe ser necesariamente inmóvil. Esto es obvio, ya que si fuese móvil, su movimiento requeriría de una causa y esta, la vez otra $\mathrm{y}$, así, hasta el infinito; existe puesto que es acto (cf. Metafísica XII, VI, 1071b, 20). Ahora bien, ese primer motor no posee materia ni magnitud. De ahí se desprende que no se podría hablar que cumple como causa eficiente (Dios creador), sino como causa final, porque podemos pensar a ese primer motor como un ser pensante que encuentra algo bueno y lo desea por sí mismo. Así, Dios mueve el universo como causa final: el objeto de los deseos. Sin embargo, sí tiene algún carácter de causa eficiente en el sentido que es de donde proviene el inicio del movimiento; entraña una total coherencia. Entonces, para aclarar esto, vale decir que ese primer motor es causa eficiente en cuanto agente y que mueve a modo de causa final.

Se nota, así, una diferencia con Spinoza, ya que la substancia creadora (Dios) sí es causa eficiente y causa primera de todas las cosas pero no se hace patente la causa final aunque parezca que sí, porque "[...] las cosas han sido producidas por Dios con suma perfección, puesto que, dada la naturaleza perfectísima, se han seguido necesariamente de ella" (Op. cit.: 90).

Sin embargo, Spinoza agrega que no se admite que Dios actúe en todas las cosas para la promoción del bien. Así, es inadmisible hablar de Dios como si hubiese optado crear, como si tuviera un propósito para hacerlo (puesto que habría voluntad y, por el Corolario I de la Proposición XXXII," Dios no obra en virtud de la libertad de la voluntad"). Donde habría cierta finalidad (ética, vale decir) es en el hombre: sería el amor hacia Dios, que es el bien supremo por el cual debemos y podemos optar (cf. Demostración de la Proposición $X X$, V Parte de la Ética). 
Aristóteles también dice que el primer motor es inmaterial y que su actividad consiste en pensar; por eso, lo define como el pensamiento del pensamiento. Así, este primer motor no podría realizar alguna acción corpórea porque su actividad es intelectual. Se sustenta con la posición de que Dios en Aristóteles es causa final y no eficiente. En Spinoza Dios es incorpóreo, sin embargo, se nota que se expresa en el mundo de forma corpórea (puesto que la extensión es un atributo de Dios) a través de los modos (inmanentismo y panteísmo): es res cogitans y res extensa, habiendo acá una diferencia patente con Aristóteles.

Los dos autores estudiados, al compararlos y como inferencia de los aspectos antes mencionados, se puede decir que Aristóteles opta por una trascendencia del principio divino cuando dice que "[...] de lo dicho resulta evidente, por consiguiente, que hay cierta entidad eterna e inmóvil, y separada de la cosas sensibles" (Metafísica XII, VII, 1073a, 3).

A diferencia de Spinoza, que se establece en el inmanentismo, puesto que Dios no existe fuera de la naturaleza porque es ella misma; todas las cosas manifiestas del mundo son atributos de esta substancia; además, se nota como tal, cuando se destruye la dualidad de Dios y el mundo que se explica psicológicamente, pero esto último no se ahondará por no ser pertinente a este artículo.

El último aspecto que se analiza es el de los accidentes en los dos filósofos estudiados.

Spinoza dice que todo lo que es, o es en sí o en otra cosa (cf. Axioma I, $1^{\text {a }}$ Parte, Ética). De esto se puede inferir que todo lo que es, o es substancia o accidente. Spinoza no habla específicamente de accidentes, sino parece que le llama modo: "Por modo entiendo las afecciones de la substancia, o sea, aquello que es en otra cosa, por lo cual también se la concibe" (Spinoza, 2004: 47).

En Aristóteles hay dos nociones de accidente: "[...] aquello que se da en algo, y su enunciación es verdadera, pero no, desde luego, necesariamente ni la mayoría de las veces $[\ldots]$ " y "[...] las propiedades que pertenecen a cada cosa por sí misma sin formar parte de su entidad [...]" (Metafísica, V, XXX. 1025 a 15).
El accidente en Aristóteles es un sentido de "lo que es" pero sería como substancia segunda, ya que estaría más cerca de lo que no es, porque no tiene existencia por sí mismo, sino que es en otro. Acá se nota que hay similitud en el significado de estas nociones Ciertamente en Spinoza los modos serían más bien como estados diversos en que se nos aparece la substancia divina, puesto que es una afección de ésta y la afección que es un modo de expresión de, cierta y determinada manera, la naturaleza de Dios (cf. Corolario de la Proposición X, $2^{\mathrm{a}}$ Parte, Ética). Con lo anterior, se podría decir que según Spinoza, pero con palabras de Aristóteles, las cosas serían accidentes de la única substancia

\section{De las convergencias}

Para finalizar y a modo de conclusión, se habla que Spinoza leyó a Aristóteles y poseía un par de obras de él, no se sabe cuáles, pero aprendió mucho, y es de lo que distingue el spinocismo de la filosofía cartesiana, se puede afirmar a modo de analogía que Spinoza representa frente a Descartes lo que Aristóteles frente a Platón. Claro está que Spinoza no es un discípulo a cabalidad de Aristóteles. A este último se le achaca la creación de la doctrina de la substancia y Spinoza la define, pero un tanto diferente del filósofo antiguo.

Donde se hace más patente la convergencia entre Aristóteles y Spinoza es en el asunto teológico. La semejanza de la substancia única spinoziana con el motor inmóvil aristotélico es poco clara, y sus diferencias son nimias. Lo que parece algo contradictorio en Spinoza es que presenta a un Dios incorpóreo y, luego que la extensión es un atributo de él, porque todo es él. En cuanto a Aristóteles, también tiene su punto débil cuando da a entender que el primer motor no es causa eficiente, si además, es principio y que toda causa es principio. Sin duda que el aporte de ambos pensadores al pensamiento metafísico es ingente. Se sabe que fueron, además, unos discípulos algo rebeldes, y que no tuvieron temor a discrepar de sus antecesores. 


\section{Bibliografía}

Abbagnano, Nicolás, (1955), Historia de la Filosofía. Barcelona: Montaner y Simón.

Aristóteles, (1994), Metafisica. Madrid: Gredos.

Brandt, Carlos, (1941), Spinoza y el Panteísmo. Buenos Aires: Kier.

Brentano, Franz, (1951), Aristóteles. Madrid: Labor.

Cambridge University Press, (1997), The Cambridge Companion to Spinoza. Cambridge: Cambridge University Press.

Copleston, Frederick, (1984), Historia de la Filosofía. Vol. I: Grecia y Roma. Barcelona: Ariel.

Dujovne, León, (1943), Spinoza su vida-su época-su obra-su influencia. Tomos II y III. Buenos Aires: Facultad de Filosofía y Letras, Instituto de Filosofía, Publicaciones de Monografías universitarias.

Falgueras Salinas, Ignacio, (1976), La "res cogitans" en Espinosa. España: EUNSA.
Gómez Caffarena, José, (1969), Metafisica fundamental. Madrid: Revista de Occidente.

Grenet, P.B., (1985), Ontología. Barcelona: Herder.

Hirschberger, Johannes, (1960), Historia de la Filosofía. Tomo II. Barcelona: Herder.

Sciacca, Michele, (1999), Estudios sobre Filosofia Moderna. Barcelona: Luis Miracle.

Spinoza, Baruch de, (1988), Tratado de la reforma del intelectol Principios de filosofía de Descartes/ Pensamientos metafisicos. Madrid: Alianza Editorial.

Spinoza, Baruch de, (1997), Ética, Tratado teológico-político. México: Porrúa.

Spinoza, Baruch de, (2004), Ética. Madrid: Alianza Editorial.

Verneaux, Roger, (1982), Textos de los grandes filósofos. Edad Moderna. Barcelona: Herder.

Windelband, W, (1951), Historia de la Filosofía Moderna. Tomo I. Buenos Aires: Nova.

Zweig, Arnold, (1939), El pensamiento vivo de Spinoza. Buenos Aires: Losada. 
- 